\title{
CHOOSING MODULATION STRATEGIES FOR 2-STAGE COMBINE LLG- AND DIRECT CONVERTER-MODELLING, SIMULATION, APPLICATION
}

The paper deals with design of switching and control strategy of 2-stage combine LLC-and matrix converter, supplied from DC voltage source. It also deals with comparison of the four different switching control modes: phase-mode control, sinusoidal PWM mode control, pulsedepletion mode control and packet-mode control. Numerical harmonic analysis for total harmonic distortion is used. Simulation and preliminary results of experimental verification are given in the paper.

\section{Introduction}

It's known that direct converters can be operated from AC network (or generator) by voltage with relative low frequency of 50-, 60-, 100-, $400 \mathrm{~Hz}$ using triac- (or thyristor) switches with phasecontrol. On the other side, matrix converters with fast IGBT and MOSFET switching devices can operate with relatively high frequencies of tens- up hundreds $\mathrm{kHz}$. The AC voltage source can be effectively created by LLC type resonant converter.

\section{Overal connection of converter system}

The block scheme of converter system is presented in Fig. 1, [1], [3].

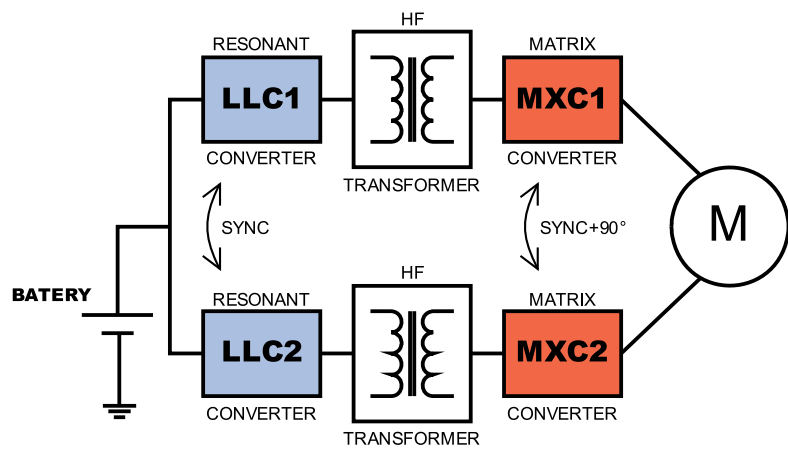

Fig. 1 Block scheme of converter system

Converter system consisting of two branches operates with two phase output voltage shifted by 90 degrees created by matrix converters MXC1 and MXC2. High frequency transformers provide galvanic insulation and increase battery voltage to the rate value for the motor. LLC resonant converters work at switching frequency of 10 - up hundreds $\mathrm{kHz}$ and must be synchronized each to other.

\section{Operation of One Single Branch}

Power circuitry scheme of converters

The main power schemes are depicted in Fig. 2.

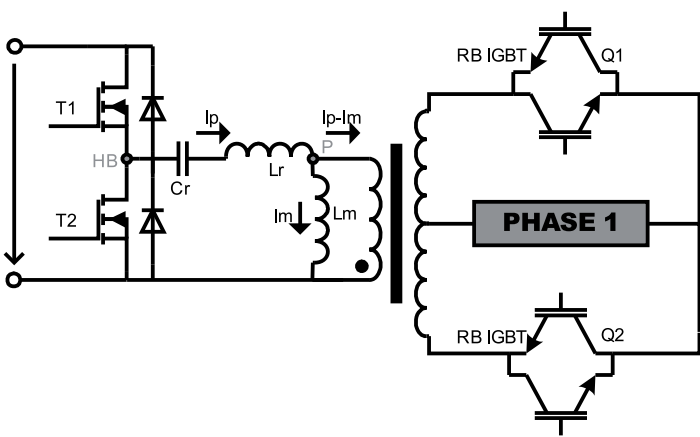

Fig. 2 Circuit diagram of single branch of the system

Operation of 1-stage LLC converter is illustrates in work [2]. Important is that converter operates at zero-voltage-switching (ZVS) mode with consequently minimal switching losses.

Design of LLC resonant converter is described in detail in [2] - [4]. Regarding to its simulated output quantities it is shown in Figs. 3 and 4 that current is well sinusoidal and the voltage can be

\footnotetext{
* Branislav Dobrucky ${ }^{1}$, Mariana Benova ${ }^{2}$, Michal Frivaldsky ${ }^{1}$, Michal Prazenica ${ }^{1}$

${ }^{1}$ Dept. of Mechatronics and Electronics, Faculty of Electrical Engineering, University of Zilina, Slovakia, E-mail: branislav.dobrucky@fel.uniza.sk

${ }^{2}$ Dept. of Theoretical Electrotechnics and Biomedical Engineering, Faculty of Electrical Engineering, University of Zilina, Slovakia
} 
sinusoidal or trapezoidal one depending on type of the load (linear or nonlinear rectifier load.

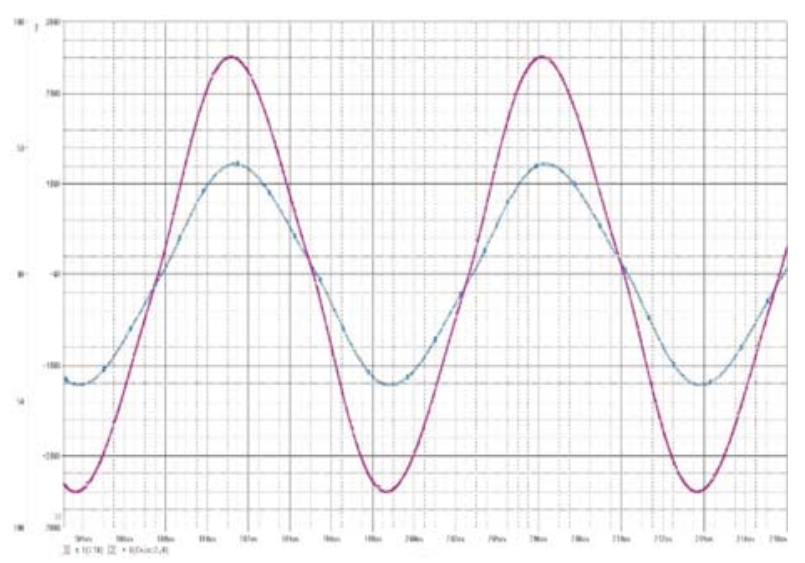

Fig. 3 Principle time waveforms of LLC converter

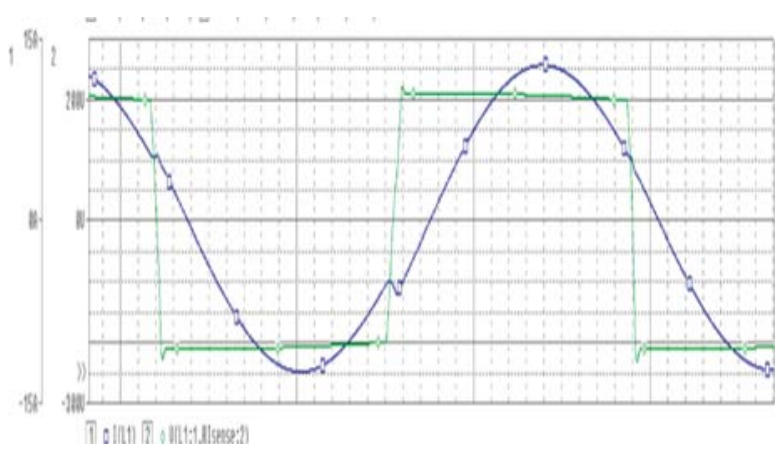

Fig. 4 Time waveforms of LLC converter at $20 \mathrm{kHz}$ frequency

Output voltage is slightly decreasing during each half-period, and at higher switching frequencies it can be more trapezoidal and distorted one according to fixed dead-time of the converter switches (see experimental section).

The second stage matrix converter can be in half- or full bridge connection. It also operates at ZVS mode. Its output voltage can be controlled by different control modes with different achieved quality.

\section{Modelling and Simulation of Half-Bridge Matrix Converter with RL Load at Different switching Strategies}

Simulated time waveforms of the output voltage and curren are shown in the next Figs. $5-8$ using different switching modes.

3.1 Phase-mode control using low frequency triac-switches and sinusoidal input voltage [7]

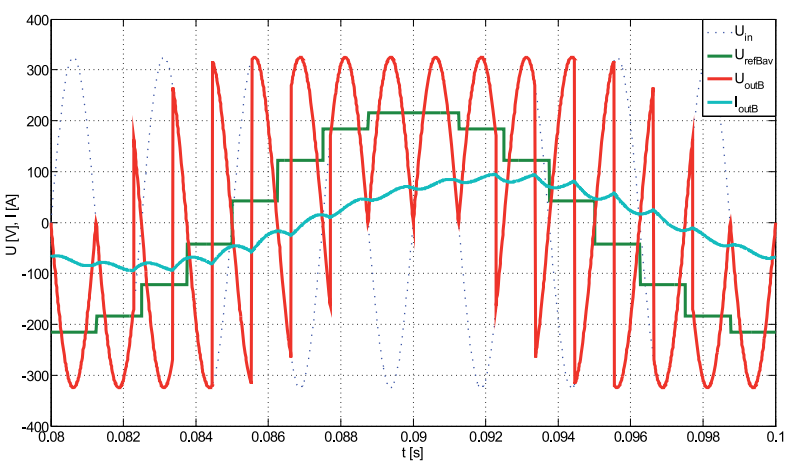

Fig. 5 Time waveforms of output voltage and current at $400 \mathrm{~Hz}$ input frequency using phase-mode control

3.2 Sinusoidal PWM mode control using fast IGBT switches and rectangular input voltage [10]

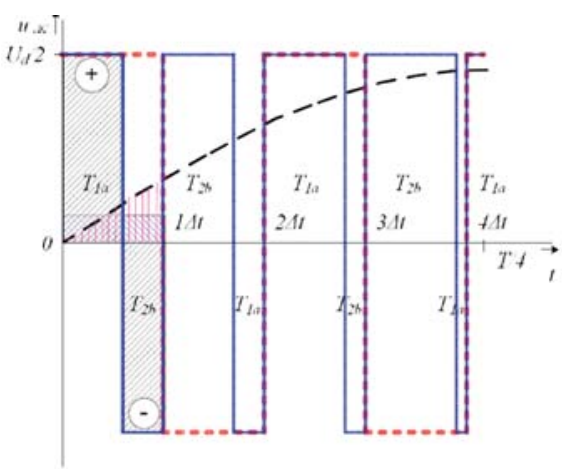

Fig. 6 Time waveforms of output voltage and current at $20 \mathrm{kHz}$ input frequency using sinusoidal PWM control

3.3 Pulse-depletion-mode control using fast IGBT switches and sinusoidal or rectangular input voltage

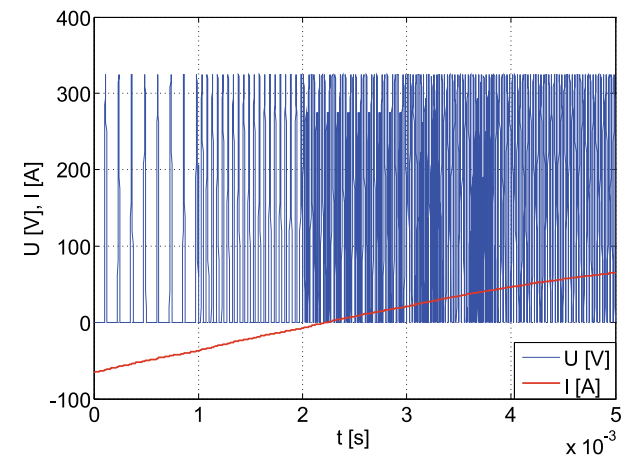

Fig. 7 Time waveforms of output voltage and current at $20 \mathrm{kHz}$ input frequency using pulse-depletion mode control

3.4 Packed-mode control using fast triac or GTO switches and sinusoidal or rectangular input voltage 
This type of control mode uses also unequal sample- and switching frequency. So, during sample interval the packet of pulses of input voltage is generated. Its average value could follow average value of reference voltage.

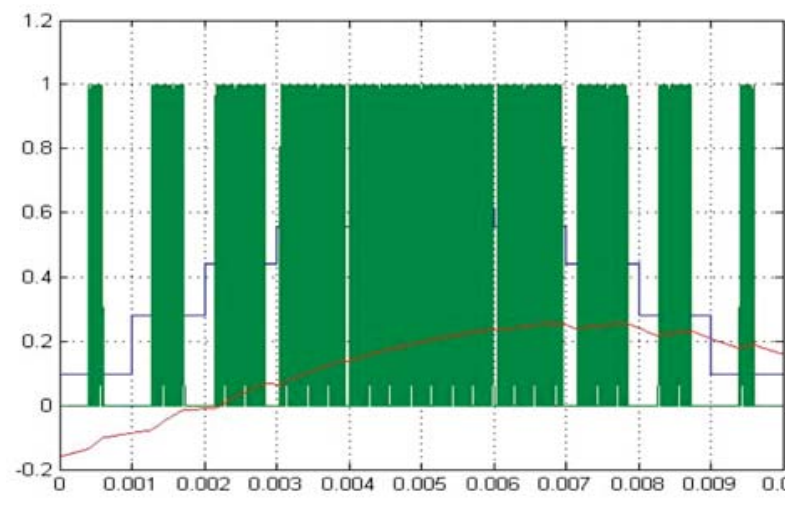

Fig. 8 Time waveforms of output voltage and current at $20 \mathrm{kHz}$ input frequency using packed mode control

\section{Qulaity of output Quantities of the Converter System Comparison Using Numerical Fourier Analysis and THD Calculation}

\subsection{Numerical analysis and THD calculation of output voltages}

The numerical Fourier analysis was used for content of harmonics of investigated voltage waveforms (detailed in appendix).

- Low frequency triac switches converter - phase control mode Calculated value of THD referred to fundamental harmonic component:

$$
T H D_{u}=U_{z} / U_{1}=1.8237 \quad 182.366 \%
$$

Calculated value of THD referred to total rms value of voltage waveform:

$$
T H D_{u}=U_{z} / U=0.8711 \quad 87.107 \%
$$

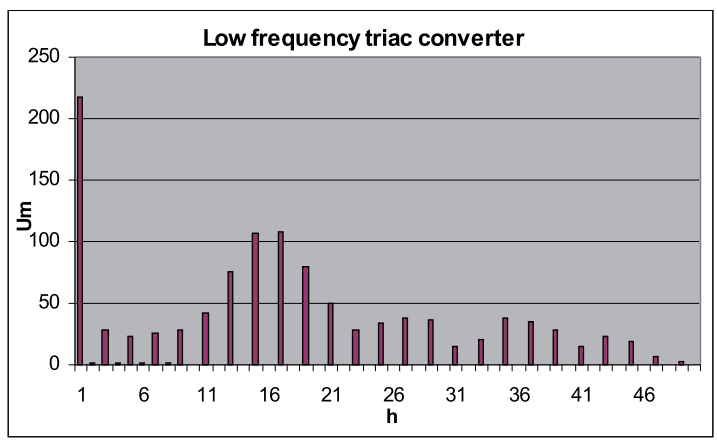

Fig. 9 Voltage amplitude spectrum of low frequency triac converter at $400 \mathrm{~Hz}$
- Fast triac/GTO switches converter - phase control

Calculated value of THD referred to fundamental harmonic component:

$$
T H D_{u}=U_{z} / U_{1}=0.8280 \quad 82.797 \%
$$

Calculated value of THD referred to total rms value of voltage waveform:

$$
T H D_{u}=U_{z} / U=0.6374 \quad 63.737 \%
$$

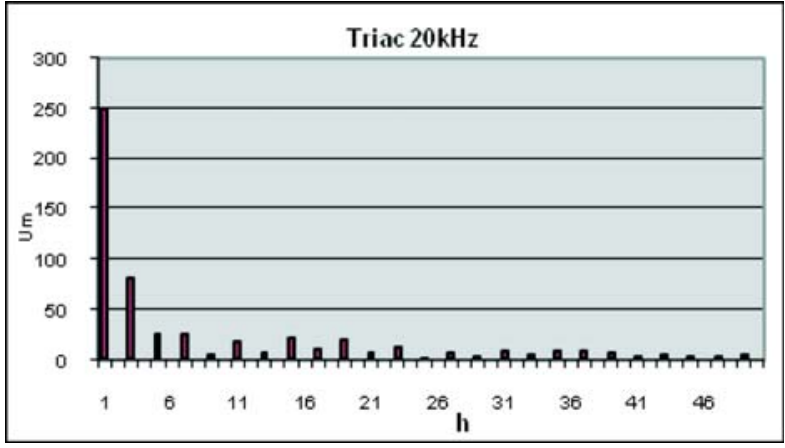

Fig. 10 Voltage amplitude spectrum of fast triac- or GTO converter at $20 \mathrm{kHz}$

- Fast IGBT switches converter - S-PWM control

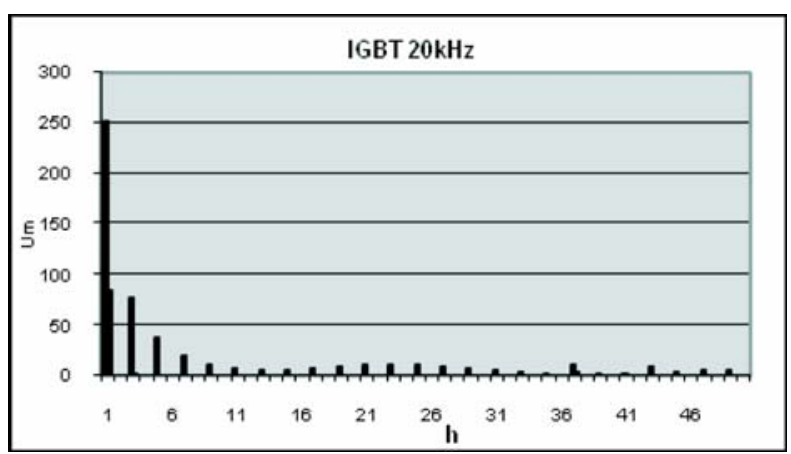

Fig. 11 Voltage amplitude spectrum of IGBT converter at $20 \mathrm{kHz}$

Calculated value of THD referred to fundamental harmonic component:

$$
T H D_{u}=U_{z} / U_{1}=0.82108 \quad 82.108 \%
$$

Calculated value of THD referred to total rms value of voltage waveform:

$$
T H D_{u}=U_{z} / U=0.63423 \quad 63.423 \%
$$

- Fast triac/GTO switches converter - depletion mode control 


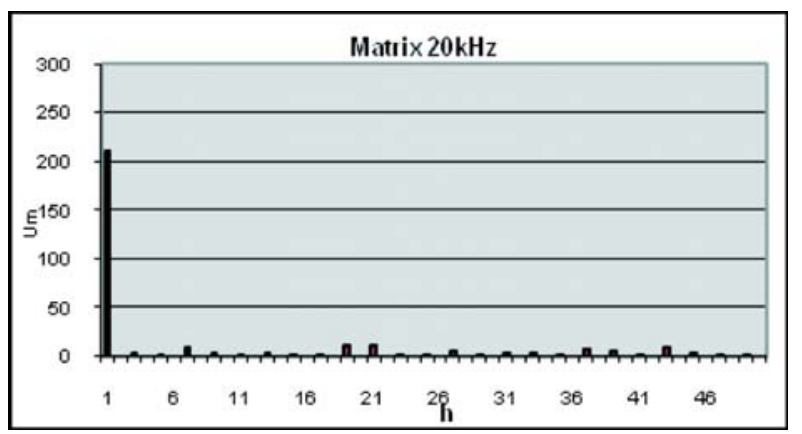

Fig. 12 Voltage amplitude spectrum of fast triac- or GTO converter at $20 \mathrm{kHz}$

Calculated value of THD referred to fundamental harmonic component:

$$
T H D_{u}=U_{z} / U_{1}=0.75474 \quad 75.475 \%
$$

Calculated value of THD referred to total rms value of voltage waveform:

$$
T H D_{u}=U_{z} / U=0.60203 \quad 60.204 \%
$$

- Fast triac/GTO switches converter - packed mode control Calculated value of THD referred to fundamental harmonic component:

$$
T H D_{u}=U_{z} / U_{1}=0.7882 \quad 78.8185 \%
$$

Calculated value of THD referred to total rms value of voltage waveform:

$$
T H D_{u}=U_{z} / U=0.6186 \quad 61.8647 \%
$$

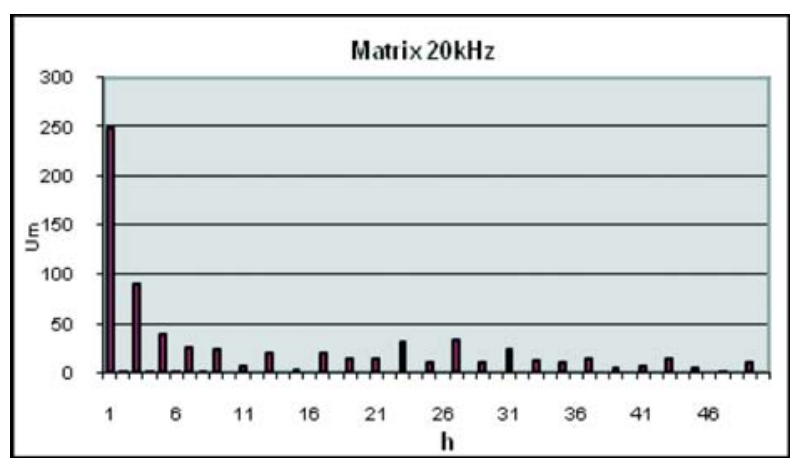

Fig. 13 Voltage amplitude spectrum of fast triac- or GTO converter at $20 \mathrm{kHz}$

\subsection{Numerical analysis and THD calculation of output currents}

The numerical Fourier analysis was also used for content of harmonics of investigated current waveforms (detailed in appendix).
Worst case calculation:

- Fast triac/GTO switches converter - packed mode control

Calculated value of THD referred to fundamental harmonic component:

$$
T H D_{I}=I_{z} / I_{1}=0.0638 \quad 6.3766 \%
$$

Calculated value of THD referred to total rms value of voltage waveform:

$$
T H D_{I}=I_{z} / I=0.0636 \quad 6.3575 \%
$$

Regarding to rather high frequency and advanced mode control the current harmonic contents are very small ones, from:

$$
T H D_{I}=I_{z} / I=0.0072 \quad 0.7209 \%
$$

up to

$$
T H D_{I}=I_{z} / I=0.0131 \quad 1.3192 \%
$$

\section{Experimentation with 2-Stage Converter System Under R-L Load}

Experimental verification was done using a single-phase LLC inverter and single-phase bridge matrix converter for test rig system, Fig. 14 and 15, respectively.

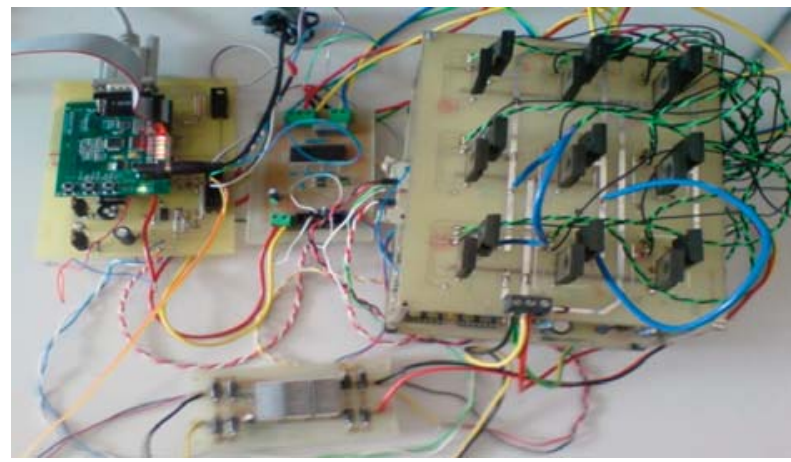

Fig. 14 Physical model of single-phase inverter and matrix converter based on [1]

Output voltage and current of first-stage LLC converter are depicted in Fig. 16a.

Output voltage and current of matrix converter stage are depicted in Fig. 16b.

The second stage was assembled with classical IGBT devices type of IRG4PH40KD, Fig. 14. It is also possible to use bidirectional types. 


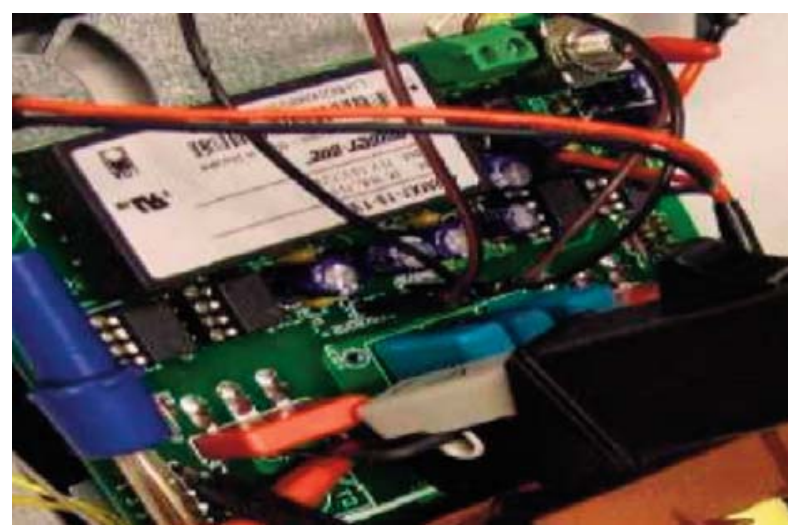

Fig. 15 Physical model of LLC - converter based on [2]

As application there are shown:

Power supply with sinusoidal output voltage in Figs. 17-18, and 2-phase electric drive with matrix converters and 2-phase induction motor in Figs. 19-20.

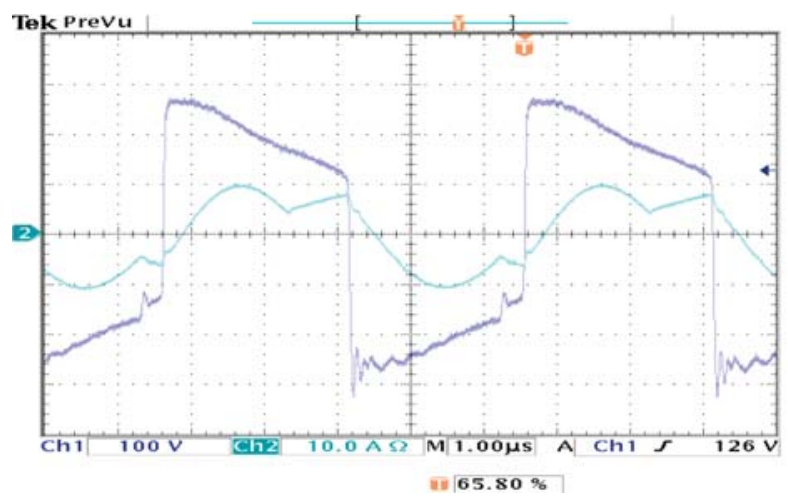

a)

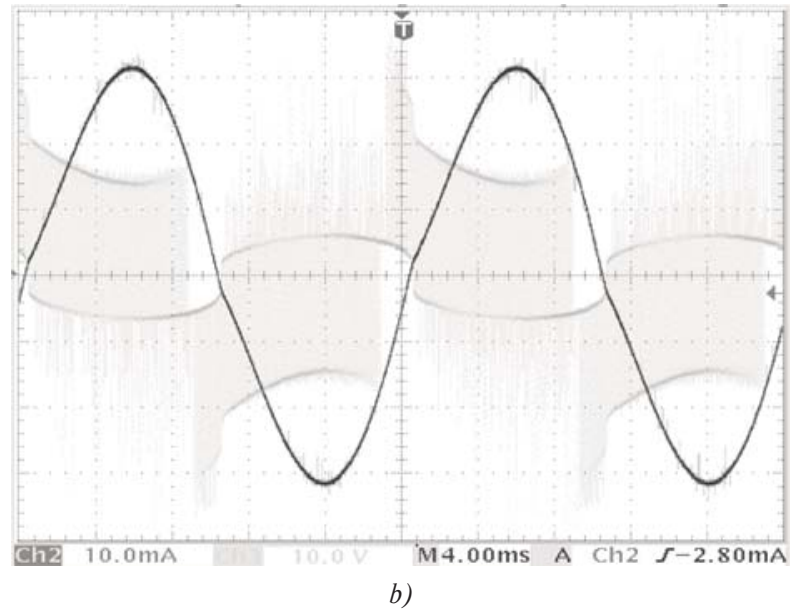

Fig. 16 Output voltage and current of the physical model of LLC converter (a), output voltage and current of the physical model of single-phase inverter and matrix converter system (b)
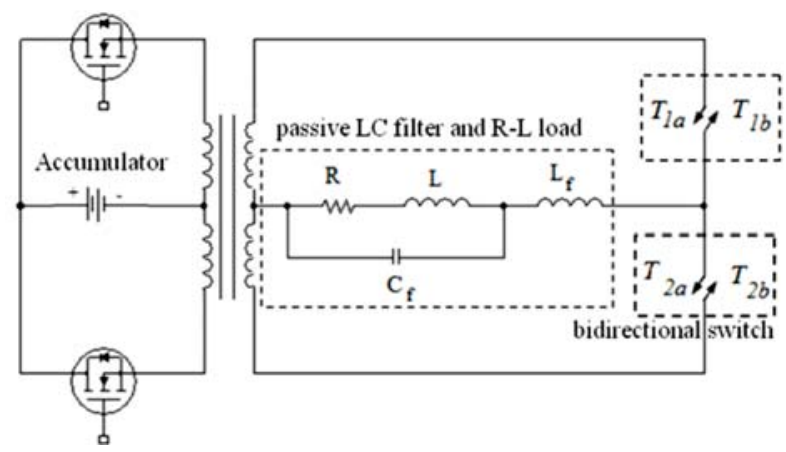

Fig. 17 Power supply with matrix converter and sinusoidal output voltage

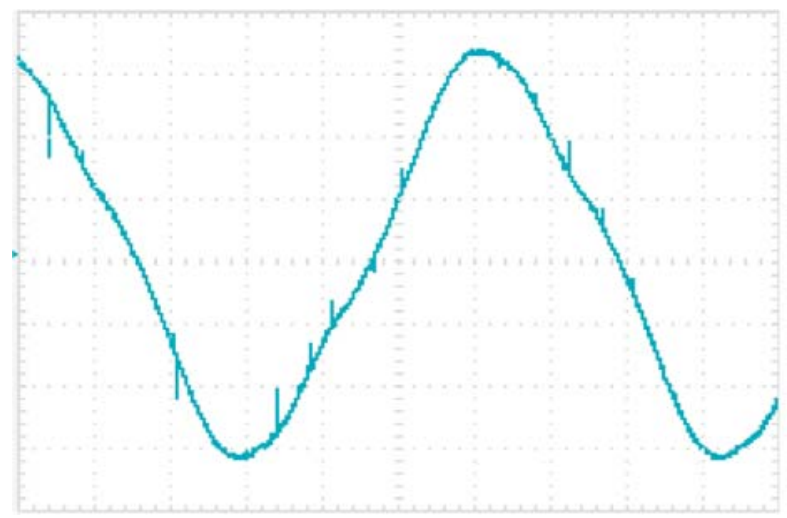

Fig. 18 Time-waveform of output voltage of the matrix converter with bipolar PWM modulation and passive LC filter

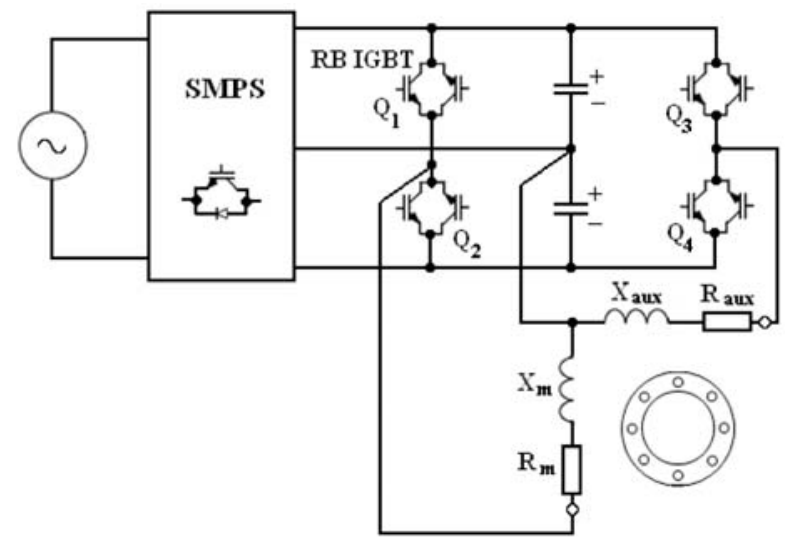

Fig. 19 Connection diagram of matrix converters and investigated 2-phase induction motor

\section{Conclusions}

The LLC-connection and the half-bridge connection of matrix converters with bipolar PWM modulation were chosen for the next 


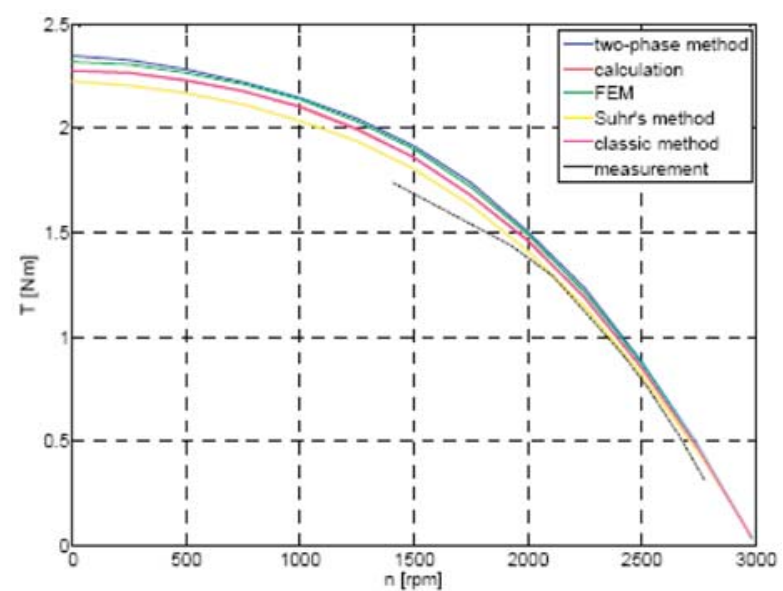

Fig. 20 Comparison between measured and simulated torque-speed characteristics of IM with two-phase supply

applications. Using of those the number of power switching elements of the two-stage converter can be reduced and smaller then those of classical three-phase voltage inverter.

Comparison of different switching mode showed that since the sinusoidal PWM mode is the best from point of view of total harmonic distortion of the output quantities, the pulse depletion mode is the most suitable from the point of view of switching losses of the converter in bridge connection. So, the trade-off between both strategies should be taken into account. Let's notice that LLC operates with soft commutation and switching-off process of matrix converters is provided by AC interlink. So, the switching-off losses of the converters are minimized, and the efficiency higher than classical connection.

Experimental verification shows very good agreement between experimental- and theoretical analysis results, so far for R-L load. Based on this it is possible to provide the design and power dimensioning of the converters.
(Fig. 14b). There are defined both amplitude- and frequency modulation ratios $m_{a}$ and $m_{f}$ as

$$
m_{n}=\frac{U_{1 m}}{U} ; \quad m_{f}=\frac{f_{s}}{f_{1}}
$$

where $U_{1 m}$ is reference amplitude of fundamental harmonic, $U$ is magnitude of supply voltage, $f_{s}$ is switching frequency, $f_{1}$ is fundamental frequency.

So, the peak amplitude of the fundamental harmonic component (equal to reference voltage) is $m_{a}$ times $U$, and varies linearly with $m_{a}$ (provided $m_{a} \leq 1$ ).

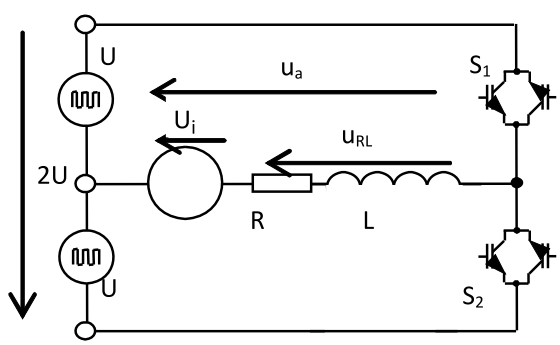

a)

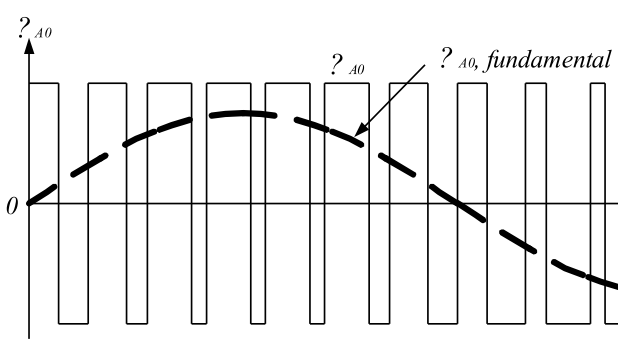

b)

Fig. 21 Single-phase half-bridge inverter (a) with PWM (b)

Then total voltage time waveform will be [8]:

$$
\begin{aligned}
u(t) & =\sum_{v=1}^{\infty} \frac{4 U_{D C}}{v \pi} \sum_{k=0}^{\frac{\left(m_{j}-2\right)}{4}-1}\left\{\left[\cos \left(v k \frac{2 \pi}{m_{f}}\right)-\cos \left(v k \frac{2 \pi}{m_{f}}+v \omega t_{s}(k)\right)\right]-\left[\cos \left(v(k+1) \cdot \frac{2 \pi}{m_{f}}-v \omega t_{s}(k)\right)-\cos \left(v k \frac{2 \pi}{m_{f}}\right)\right]+\right. \\
& \left.+\left[\cos \left(v \frac{2 \pi}{m_{f}} \frac{m_{f}-2}{4}\right)-\cos \left(v\left(\frac{2 \pi}{m_{f}} \frac{m_{f}-2}{4}+\frac{\pi}{m_{f}}\right)\right)\right]\right\} \cdot \sin (v \omega t)
\end{aligned}
$$

\section{APPENDIX - Voltage- and Current Analysis of AC/AC Half -} Bridge Matrix Converter System

Equivalent circuit diagram of half-bridge single phase converter (one of two-phase orthogonal systems) is depicted in Fig. 21a, and bipolar pulse-width modulation in Fig. 21b.

Switching-pulse-width can be determined based on equivalence of average values of reference waveform and resulting average value of positive and negative switching pulses during switching period where switching instant is equal to:

$$
t_{s}(k)=\frac{1}{2 U_{D C}} \cdot S_{\Delta}(k)+\frac{T_{s}}{2}
$$

and

$$
t_{s}\left(\frac{m_{f}-2}{4}\right)=\frac{T_{s}}{2}
$$

and $S \Delta(k)$ is area under sinewave during k-switched interval: 


$$
\begin{aligned}
& S_{\Delta}(k)=U_{m} \frac{m_{f}}{2 \pi}\left[\cos \left(\frac{2 \pi}{m_{f}} k\right)-\cos \left(\frac{2 \pi}{m_{f}}(k+1)\right)\right] \\
& S_{\Delta}\left(\frac{m_{f}-2}{4}\right)=U_{m} \frac{m_{f}}{2 \pi}\left[\cos \left(v \frac{2 \pi}{m_{f}} \frac{m_{f}-2}{4}\right)-\cos \left(v\left(\frac{2 \pi}{m_{f}} \frac{m_{f}-2}{4}+\frac{\pi}{m_{f}}\right)\right)\right]
\end{aligned}
$$

The frequency modulation ratio $\mathrm{mf}$ should be an odd integer Choosing $m f$ as odd integer results in an odd symmetry $[f(-t)=$ $=-f(t)]$ as well as half-wave symmetry $\left[f(-t)=-f\left(t+T_{s} / 2\right)\right]$ with the time origin shown in Fig. 17b. Therefore, only odd harmonics are present and the even harmonics disappear from the wave form of $u_{a}$. Moreover, only the coefficients if the sine series in Fourier analysis are finite; those for the cosine series are zero.

\section{Acknowledgement}

The authors wish to thank for the financial support to the Education operational program Centre of Systemization of advanced technology and knowledge transfer between industrials sphere and university environment No. ITMS 26110230004 funded by European regional development fund (ERDF), and VEGA project No. 1/0470/09.

\section{References}

[1] PRAZENICA, M., DOBRUCKY, B., BENOVA, M., KASSA, J.: Comparative Study of 2-phase Low Frequency Triac Converterand High Frequency Two-stage Matrix Converter Systems, Elektronika in Elektrotechnika T 190, No. 4(100), 2010, ISSN 1392 1215 , pp. 15-20.

[2] FRIVALDSKY, M., DRGONA, P., PRIKOPOVA, A.: Design and Modeling of 200 kHz 1,5kW LLC Power Semiconductor Resonant Converter, IEEE Int'l Conf. on Applied Electronics, PLZEN 2009, ISBN 9788070437810, pp. 111-114.

[3] SZYCHTA, E.: Multi-resonant ZVS DC-DC Converters (in Polish). Monograph, Publish Office of the University of Zielona Gora (PL), 2006, ISBN 83-7481-040-08.

[4] LUFT, M., SZYCHTA, E.: Commutation Processes in Multiresonant ZVS Bridge Converter, AEEE - Advances in Electrical and Electronic Engineering, University of Zilina (SK), No. 1-2, Vol. 7/2008, pp. 84-91, ISSN 1336-1736.

[5] DOBRUCKY, B., SPANIK, P., KABASTA, M.: Power Electronics Two-Phase Orthogonal System with HF Input and Variable Output, Elektronika ir Elektrotechnika, 2009, No. 1(89).

[6] DOBRUCKY, B., BENOVA, M., SPANIK, P.: Using Complex Conjugated Magnitudes - and Orthogonal Park/Clarke Transformation Methods of DC/AC Frequency Converter, Electronics and Electrical Engineering, Vol. 93 (2009), No. 5, Kaunas (LT), pp. 29-34 ISSN 1392 - 1215.

[7] JEEVANANTHAN, S., DANANJAYAN, P., MADHAVAN, R.: Novel Single-Phase To Single-Phase Cyclo-conversion Strategies: Mathematical and Simulations Studies, Int'l J. of Power and Energy Systems, Vol. 27(2004), No. 4, pp. 414-423 ISSN 1078-3466.

[8] ZASKALICKY, P., ZASKALICKA, M.: Behaviour of the Two-phase Permanent Magnet Synchronous Motor Supplied by Triacs from Single-Phase Voltage, Acta Electrotechnica et Informatica, TU Kosice (SK), Vol. 5 (2005), No. 3, pp. 1-5, ISSN 1335-8243.

[9] BLAABJERG, F. et al.: Evaluation of Low-Cost Topologies for Two-Phase IM Drives in Industrial Application, Record of $37^{\text {th }}$ IEEE IAS Annual Meeting on Industry Application, Vol. 4, pp. 2358-2365, ISSN 0197-2618.

[10] BENOVA, M., DOBRUCKY, B., SZYCHTA, E., PRAZENICA, M.: Modelling and Simulation of HF Half-Bridge Matrix Converter System in Frequency Domain, Logistyka, 2009, No. 6, ISSN 1231-5478, pp.87.

[11] DOBRUCKY, B., BENOVA, M., MARCOKOVA, M., SUL, R.: Analysis of Bipolar PWM Functions Using Discrete Complex Fourier Transform in MATLAB, Proc. of Technical Computing Prague 2009, Praha (CZ), Nov. 2009, pp. 22, ISBN: 978-80-7080-733-0

[12] BALA, S., VENKATARAMANAN, G.: Matrix Converter BLDC Drive using Reverse-Blocking IGBTs, Proc. of IEEE APEC '06 Int'l Conf., Dallas, Texas (US), March 2006, pp. 660-666. 